\title{
The characteristics of types and annual trends of pop-up fashion stores \\ - Focused on domestic cases -
}

\author{
Jihun $\mathrm{Yu}^{\dagger}$ and Doree $\mathrm{Choi}^{*}$ \\ Dept. of Clothing \& Textiles, Sangmyung University, Korea \\ Dept. of Human Environmental Science, The Graduate School of Sangmyung University, Korea*

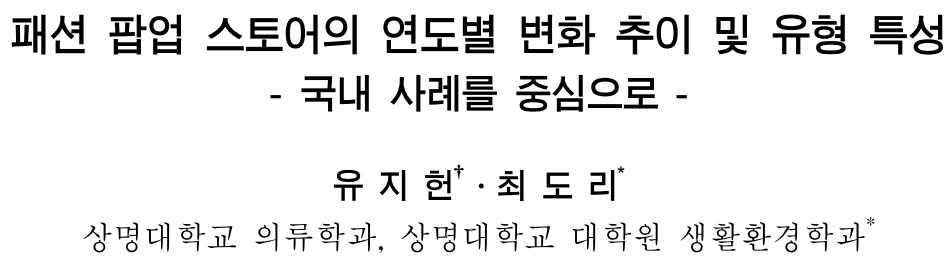

\begin{abstract}
Contemporary fashion companies have been planning marketing strategies that can promote brands and products more effectively for satisfying consumers' increasingly diversified needs. For this reason, retail spaces have continued to evolve and the modern concept of pop-up stores appeared through this process. Therefore, the object of this study was to research domestic pop-up fashion store cases by collecting article data. These data are from Internet fashion-specialty sites and analyze the types and characteristics of pop-up fashion stores by providing basic information that will be useful in the pop-up fashion stores of companies when they establish their marketing strategies. This study utilized the content analysis method and derived the results by using SPSS Statistics. As a result of this study, the type of "pop-up fashion stores opening in distribution enterprises" comprised the highest percentage of the whole store types and the pop-up fashion stores' management purposes were focused on product introduction, promotion, and market testing. As time passed, not only did pop-up fashion stores' growth rate increased, but also the types of pop-up fashion stores have become more diverse. In other words, contemporary fashion companies are utilizing more pop-up fashion stores as a marketing strategy than before. However, due to the short history of domestic pop-up fashion stores, the variety of research is still insufficient, so more extensive research on pop-up fashion stores is required.
\end{abstract}

Keywords: fashion pop-up stores(패션 팝업 스토어), types(유형), characteristics(특성), domestic(국내의), case (사례)

\section{Introduction}

과거에서 현대에 이르기까지, 소비자의 욕구는
매우 다차원적으로 변해왔다. 단순히 필요한 제품을 구매하기 위해 쇼핑하던 이전과는 달리, 쇼핑하는 것 자체를 즐기게 되면서, 더 이상 쇼핑이 어떤 목적

Received 8 May 2015, revised 23 October 2015, accepted 26 October 2015.

본 연구는 2015년도 상명대학교 교내연구비를 지원받아 수행하였음.

${ }^{+}$Corresponding author (jyu@smu.ac.kr) 
을 위한 수단인 것이 아니라, 쇼핑 자체가 목적이 되 었고, 쇼핑을 통해 느끼는 감성과 체험을 중요시하 는 분위기가 증가하고 있는 추세다. 이런 변화는 패 션을 소비함에 있어서도 다르지 않다. 국 - 내외적으 로 패션 브랜드가 급증하면서 제품의 질, 가격, 디자 인 등 제품이 가진 특성만으로는 수많은 패션 브랜 드 사이에서 경쟁력을 갖기가 힘들어졌다. 이 때문 에 패션 기업들은 소비자에게 차별화된 감성과 체 험을 제공함으로써 보다 효과적으로 브랜드와 제품 을 홍보하고자 하는 움직임을 보이고 있다. 이런 변 화는 리테일 공간에도 변화를 가져다주었는데, 팝업 스토어 또한 이와 같은 맥락에서 이용되고 있는 리 테일 스토어의 한 형태라고 할 수 있다(Chae, Choi, Jang, \& Ko, 2012). 팝업 스토어는 단기간에 전 세계 적으로 익숙한 리테일 공간으로 자리 잡았을 만큼 매우 활발히 운영되고 있으며, 앞으로도 더욱 많은 패션기업에서 활용할 것으로 전망된다.

그동안 국내에서 수행된 팝업 스토어에 관한 연 구로는, 패션 브랜드와 식음료 브랜드의 이종업체 간 팝업 스토어에 대한 비교 연구(Kim, J. S., 2010) 와 팝업 스토어 방문자에 대한 체험 감성 분석 및 구매행동 분석 $(\mathrm{Kim} \& \mathrm{Kim}, 2011)$ 이 수행되었으며, 그 외에 팝업 스토어의 점포 속성이 소비자의 태도 와 재방문 의도에 미치는 영향(Chae et al., 2012), 팝 업스토어의 공간적 특성에 관한 연구 $(\mathrm{Kim} \& \mathrm{Lee}$, 2012; Shin, 2013)등과 같이 부분적 연구가 이루어 졌을 뿐, 팝업 스토어에 대한 전반적이고 실질적인 조사 연구는 이루어지지 않았다. 특히, 국내 팝업 스 토어의 소수 몇 가지 사례에 초점을 맞춘 경우가 대 부분이었으므로, 보다 광범위한 사례를 바탕으로 한 일반적 특성이나 시간의 흐름에 따른 패션 팝업 스 토어의 특성 및 진화상을 파악하기에는 한계가 있 었다. 이에 반해, 국외에서는 '팝업 스토어로의 마케 팅 접근(Marciniak \& Budnarowska, 2009)', '템포러 리 스토어: 패션 브랜드를 위한 새로운 마케팅(Surchi, 2011)', ‘혁신적 비즈니스 전략으로써 팝업 소매점 의 가능성과 소비자 쇼핑 경험의 강화(Niehm, Fiore, Jeong, \& Kim, 2006)' 등과 같은 연구에서 팝업 스 토어의 정의 및 유래 그리고 역할 등을 탐색해보고, 패션 브랜드에서의 도입 사례 및 패션 산업에서의 새로운 마케 팅 가능성을 조망해보는 연구가 이루어
졌으며, 'FOM(Foreign Operation Mode)으로써의 팝 업 스토어에 대한 연구(Picot-Coupey, 2014)'에서는 해외 시장을 겨낭한 팝업 스토어의 특성 및 국제 관 계 리테일 프로세스에서 $\mathrm{FOM}$ 을 기반으로 한 팝업 스토어의 역할에 대한 조사 연구가 이루어졌다.

그러나 팝업 스토어의 개념이 등장한 지 불과 10 년 남짓 되었고, 특히 국내 패션 브랜드에서 팝업 스 토어를 마케팅 도구로 이용하기 시작한 것은 더욱 이 오래되지 않았을 뿐만 아니라, 패션기업에서도 타국의 팝업 스토어 운영 형태를 외적으로 도입하 여 활용한 상태이기 때문에, 팝업 스토어에 대한 정 의와 설립 목적, 대상, 설립 위치 그리고 설립 방법 뿐만 아니라, 그 유형 분류가 학문적으로 정립되어 있지 않은 실정이다.

따라서 본 연구에서는 팝업 스토어에 대한 개념 및 유래를 고찰하고, 국내 패션 팝업 스토어의 다양 한 사례를 수집하여 운영 형태와 목적을 분석한 후, 그 유형을 분류 시도해 보고자 한다. 또한, 국내에서 운영된 팝업 스토어의 횡적 변화 추이를 파악해 봄 으로써 앞으로 패션기업들이 팝업 스토어를 패션 마케팅 전략의 수단으로써 보다 효과적으로 활용할 수 있도록 도움을 주고자 하며, 패션 팝업 스토어에 대한 학문적 연구의 기초자료를 제공하는데 목적을 두고자 한다.

\section{Background}

\section{Development and the characteristics of pop-} up stores

오늘날 우리는 복잡한 최첨단의 상업적 거래에 의해 정체성과 본래의 의미를 상실한 유동적 사회 (liquid society)에서 살고 있으며(Bauman \& Favaro, 2010), 그러한 사회적 구조가 유통과 통신 수단의 변화를 초래하였고, 이런 과정에서 등장한 매장 형태 중 하나가 팝업 스토어라고 할 수 있다. Di Sabato (2009)는 팝업 스토어를 오락, 지식, 경험의 논리를 반영한 통신과 판매의 종합이라 할 정도로 팝업 스토 어의 중요성을 강조하였다(as cited in Surchi, 2011). 팝업 스토어는 상시 운영되는 보통의 매장과는 달리 일정 기간 동안만 운영되는 매장으로, 인터넷 의 예기치 않은 팝업창과 유사한 특성을 지닌다고 
하여 붙여진 용어이다(Kim, J. S., 2010). 이 용어는 트렌드 분석 회사인 '트렌드 워칭'이 2004년에 새로 운 트렌드 경향으로 '팝업 리테일'을 제안하면서 광 범위하게 사용되기 시작했으며, ‘팝업 스토어', ‘팝 업 샵, ‘게릴라 마케팅', ‘팝업 리테일’ 또는 '템퍼러 리 스토어’라고 불리기도 한다(Kim, J. S., 2010).

미국의 대형 디스카운트 스토어인 타깃은 2002 년 뉴욕 맨해튼에 신규 매장을 오픈하려고 하였으 나, 공간 확보에 실패하자, 임대 부지에 단기간 임시 매장을 열었는데, 이 매장을 통해 예상치 못했던 높 은 매출을 올리게 되었고, 여기서부터 '팝업 스토어' 의 개념이 정립되기 시작하였다(Kim, J. S., 2010). 이 후, 타깃에서부터 시작된 초기형태의 팝업 스토 어는 브랜드 철학과 이벤트를 담아낸 꼼데가르송의 게릴라 스토어, GAP이 진행한 아티스트와의 콜라 보레이션 팝업 스토어 등을 거치면서 조금씩 진화 된 모습을 갖추게 되었다(Kim \& Lee, 2012).

팝업 스토어는 짧은 기간 동안 특별한 장소에서 운영되며, 주로 콜라보레이션 제품, 리미티드 제품, 신상품 등을 판매하거나 전시하고, 다양한 아이디어 와 이벤트로 꾸며지며, 이런 점에 있어서 매장의 시· 공간적인 요소와 판매되는 제품, 이벤트 등의 '한 정성'과 ‘일시성'이 극대화된다(Kim \& Lee, 2012). 이 처럼 한시적으로 운영되는 팝업 스토어는 단기간에 판매율과 방문 소비자 수를 확보할 수 있어야하기 때문에, 주로 유동인구가 많은 지역에 설치 및 운영 되며, 국내에서는 대부분 홍대, 가로수길, 명동, 강 남역 등의 번화가에 위치하고 있다(Lim, 2012). 기 업에서는 이런 팝업 스토어 오픈 자체를 '이슈화'시 켜 소비자로 하여금 브랜드 이미지를 제고시키고, 소비자들 간의 입소문을 통한 구전 홍보 효과를 거 둘 수 있을 뿐만 아니라, 궁극적으로는 단기간에 높 은 매출을 올릴 수 있는 수단으로 이용할 수 있다 (Jang, 2012). 또한, 팝업 스토어 매장은 임시로 운영 되는 공간이므로 정식 매장을 오픈하는 것에 비해 임대료나 인테리어에 드는 비용이 적고, 적은 양의 집기와 상품만으로도 운영이 가능하다. 그러므로 기 업에서는 본격적인 매장 오픈이나 제품 판매에 앞 서 소비자의 반응을 미리 살펴보는 '마켓 테스트'를 위해 팝업 스토어를 이용하기도 한다(Jang, 2012; Kim \& Kim, 2011).
반면, 소비자 입장에서는 일정 기간 동안만 오픈 하고 사라지는 방식으로 신선한 구매 환경과 즐거 움을 체험할 수 있으며, 이를 통해 긍정적이고 친밀 한 브랜드 이미지와 새로운 제품 정보를 지니게 됨 으로써 미래의 구매를 위한 정보지식을 획득하게 될 것이다.

오늘날의 팝업 스토어는 다양한 브랜드, 아티스 트, 공연, 예술 등과의 협업으로 진화하고 있다 $(\mathrm{Kim}$ \& Kim, 2013). Lisanti(2014)는 이러한 팝업 스토어 가 소비자 조사, 브랜드 관심, 제품 전시, 브랜드 홍 보, 팬 업무, 연중 기념행사 그리고 제품 직거래 등 과 같은 현 시대의 리테일 트렌드를 반영하고 있다 고 하였다.

즉, 단순히 일시적인 판매를 위한 '임시매장'에 불 과했던 팝업 스토어는 시간이 지나면서 브랜드 이 미지를 보여주고, 매출을 올릴 수 있는 중요한 마케 팅 수단으로 발전하고 있다.

\section{The types of pop-up stores}

이태리 로마 대학의 Micaela Surchi 교수는 팝업 스토어의 컨셉은 브랜드, 시장 그리고 관리의 특별 함에 의해 여러 형태로 분류되어질 수 있다고 하였 으며, 이러한 컨셉을 기초로 팝업 스토어의 유형을 '게 릴라 스토어(Guerrilla stores)', ‘유목형 스토어(Nomad stores)', '일시적 온라인 스토어(Temporary online stores)' 그리고 ‘일시적 아웃도어 사이트(Temporary outdoor sites)'로 분류하였다(Surchi, 2011).

$\operatorname{Kim}$ and $\operatorname{Kim}(2013)$ 의 연구에 따르면, '게릴라 스 토어'는 패션의 중심지가 아닌, 대도시의 교외 지역 에서 비싼 광고 캠페인 없이 시작되었다. 브랜드 '꼼 데가르송'이 2004년 베를린에서 첫 번째 게릴라 스 토어를 전개하였는데, 이 스토어에서는 주로 최신 콜렉션과 독점 라인이 선보여졌다. Subvertising(2009) 은 게릴라 스토어가 하나의 소매 전략에 지나는 것 이 아니라, 소비자와 소통하는 하나의 새로운 수단 이라고 하였다.

‘유목형 스토어'는 매장 점포가 아닌 목표 시장에 도달하기 위해 한 지역에서 다른 지역으로 브랜드 디스플레이를 이동시키는 화물차 개념이다. 브랜드 '푸마'는 샵, 카페 그리고 2개의 테라스와 사무실로 구성된 화물차 매장으로 전 세계를 돌았는데, 이를 
통해 그들은 방문객에게 브랜드를 통해 가질 수 있 는 최대 경험을 전달하고자 하였다(Surchi, 2011).

'일시적 온라인 스토어'는 템포러리 스토어의 전 략적 장점과 인터넷의 소통적 상호작용 혜택을 혼 합한 스타일이다. 이 스토어의 장점은 하나의 인터 넷 사이트를 통해 가능한 모든 시장에 접근할 수 있 으며, 스토어의 운영이 매우 용이하다는 점이다. 대 표적인 사례로는 가방과 패션 액세서리 브랜드 '만 다린 덕'의 온라인 팝업 스토어가 있는데, '만다린 덕'은 2008년 크리스마스에 이와 같은 형태의 온라 인 스토어를 런칭하여 세 달 동안 잠재 고객에게 이 미지 및 컬러 옵션, 가격과 주문 번호를 제공하였으 며, $50 \%$ 의 할인 혜택까지 제공하였다(Surchi, 2011).

'일시적 아웃도어 사이트'는 임시 매장의 주요 특 성, 즉, 단독 브랜드, 한정판매, 선정 지역 등을 공유 하는 개념이다. 대표 사례로, 2008년 밴쿠버에서 열 린 $10 \mathrm{~km}$ 경주에 '나이키'가 참여하였는데, 나이키 의 목적은 참여자들에게 프리 마사지, 음료수, 스넥 그리고 새로 나온 나이키 런닝화를 제공하면서 그 들에게 '용기'를 주는 것이었다.

이와 유사한 팝업 스토어의 유형을 다룬 국내 연 구로는, 게슈탈트의 법칙을 바탕으로, 팝업 스토어 를 ‘고정형'과 ‘유동형'으로 나눈 연구(Shin, 2013) 가 있으며, 팝업 스토어의 공간적 특성을 이동성 (Mobility), 다양성(Diversity), 가변성(Flexibility), 일 시성(Impermanence), 이벤트성(Performance)으로 제 시한 연구(Kim \& Lee, 2012)도 있었다.

이와 같이 팝업 스토어는 공간의 이동성, 다양성, 가변성과 행사의 일시성, 이벤트성 등으로 분류할 수도 있고, 활용 공간의 형태 및 소유 개념에 따라 세분화 할 수도 있을 것이다.

Kim, S. Y.(2010)은 국내 패션 멀티브랜드 스토 어의 유형에 대한 연구에서, 멀티브랜드 스토어 전 문가와의 심층면접을 통해 '구성 상품(MD) 카테고 리에 의한 분류', ‘스토어 아이덴티티(Store Identity) 에 의한 분류', '운영 주체에 의한 분류'와 같이, 세 가지의 멀티브랜드 스토어 분류 기준을 제시하였는 데, 패션 팝업 스토어 또한 패션 제품을 판매 및 홍 보하는 개념의 매장이라는 점에서, 팝업 스토어를 구성하는 상품군에 따라 분류할 수 있을 것이며, 매 장 운영 주체에 따라 팝업 스토어의 존재 이유, 운영
의도, 운영 방식 역시 달라질 수 있기 때문에, 운영 주체에 따른 분류 역시 가능하리라 본다.

전 세계적으로 팝업 스토어에 대한 관심이 고조 되면서 팝업 스토어의 형태가 다변화 되고 있으므 로 그 특성에 따라 유형을 분류하고, 시간 흐름에 따른 변화추이를 파악하는 작업은 의의가 있을 것 이다.

\section{Methods}

\section{Data collection and analysis}

본 연구는 ‘패션넷코리아', ‘삼성디자인넷', ‘패션 채널', '어패럴 뉴스' 등의 인터넷 패션 전문 사이트 의 기사로부터 실제로 운영되었던 패션 팝업 스토 어에 대한 자료를 수집하여 내용 분석법을 활용하 였으며, 자료 분석은 SPSS Statistics 21 통계 프로그 램을 이용해 기술통계 및 빈도분석, 교차분석 등을 실시하였다. 연구 대상의 범위는 패션 팝업 스토어 가 처음으로 기사화된 2007년도 사례부터 2014년 12 월의 사례까지 총 242 개로 한정하였다.

이와 같이 수집된 기사의 본문에서 명시하고 있 는 각 패션 팝업 스토어 사례의 브랜드 명, 판매 제 품, 운영 목적, 운영 장소 및 시기 등의 객관적인 정 보를 토대로 패션 팝업 스토어의 유형을 본 연구의 목적에 부합하도록 도출하고, 이에 대한 누적 현황 과 연도별 변화 추이를 분석하였다.

또한, 본 연구에서는 패션 팝업 스토어의 유형 도 출을 위해 $\operatorname{Kim}(2010), \mathrm{Kim}$ and $\operatorname{Lee}(2012)$, 그리고 $\operatorname{Shin}(2013)$ 등의 선행 연구 분류 틀을 기준으로, 패 션 전공 교수 1 명, 석사과정 대학원생 4 명, 박사과정 대학원생 1 명이 참석한 회의를 통해 분류 작업을 시 행하였다. 전체 242 개의 사례가 다섯 번의 회의를 통해 1 차 분류되었으며, 여덟 번의 회의를 통해 이 를 다시 비슷한 특성을 지닌 유형끼리 묶어 최종 유 형을 도출하는 2 차 분류 작업이 시행되었다.

\section{Research questions}

본 연구의 목적인 국내 패션 팝업 스토어의 유형 및 특성을 운영 주체, 패션존, 매장 형태 및 운영 목 적에 따라 분류 분석하고자, 다음과 같은 연구문제 를 설정하였다. 
[연구문제 1] 운영주체에 따른 패션 팝업 스토어 의 유형 및 연도별 변화 추이를 파 악한다.

[연구문제 2] 패션 팝업 스토어의 패션존 현황 및 변화 추이를 파악한다.

[연구문제 3] 공간 형태에 따른 패션 팝업 스토어 의 유형을 분류한다.

[연구문제 4] 패션 팝업 스토어의 공간 형태 현황 및 변화 추이를 파악한다.

[연구문제 5] 운영 목적에 따른 패션 팝업 스토어 의 유형을 분류한다.

[연구문제 6] 패션 팝업 스토어의 운영 목적 현황 및 변화 추이를 파악한다.

\section{Results}

\section{Types and annual changes of fashion pop-} up stores by operators

국내 패션 팝업 스토어와 관련된 수집 자료의 분 석 결과, 팝업 스토어의 운영 주체는 크게 패션기업 과 유통업체로 나뉘었다. 이와 같은 운영 주체의 차 이에 따라, 운영 의도 및 매장의 존재 이유, 운영 방 식이 달라진다. 패션기업이 주체일 경우, 자사 브랜 드의 팝업 스토어를 오픈하는 반면, 유통업체가 주 체일 경우, 하나의 브랜드 혹은 여러 브랜드의 팝업 스토어를 자사 유통업체에 입점시키는 운영 방식을 채택하고 있다. 따라서 본 연구에서는 운영 주체에 따라 팝업 스토어를 '패션기업 주체', ‘유통업체 주 체'와 같이 두 유형으로 나누어, 패션 팝업 스토어의 연도별 변화 추이를 분석하였다.

국내 패션 팝업 스토어의 연도별 추이를 알아보 기 위해 전체 242개 사례를 대상으로 운영 시기에 대한 빈도 분석을 실시하였으며, 그 결과는〈Fig. 1〉 과 같다.

패션기업 주체 팝업 스토어는 2007년에 처음으 로 등장했으며, 2009년부터 본격적으로 '구호', '나 이키' 등의 패션기업에서 팝업 스토어를 선보이기 시작하여 2012년까지 그 수가 지속적으로 증가하였 다. 2013년에는 패션기업 팝업 스토어의 수가 전년 대비 $14.4 \%$ 증가하였고, 2014년에도 전년 대비 $10.9 \%$ 증가하면서 패션기업 주체 팝업 스토어의 수가 급

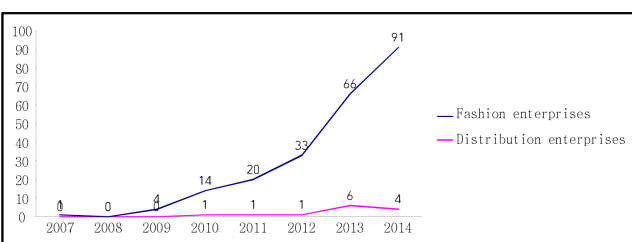

〈Fig. 1〉 The annual changes of fashion pop-up stores managed by fashion enterprises and distribution enterprises

격히 증가하였다.

반면, 유통업체에서는 패션기업보다 3년 늦은 시 점인 2010년에 처음으로 팝업 스토어를 오픈하였으 며, 유통업체 팝업 스토어 또한 2013년부터 이전에 비해 높은 비율로 증가하여 이때부터 팝업 스토어 가 패션기업과 유통업체에서 하나의 마케팅 트렌드 로 자리 잡았음을 알 수 있다.

\section{The situation and annual changes of fashion} pop-up stores' fashion zone

국내 패션 팝업 스토어에서 전개하고 있는 패션 존(fashion zone) 현황을 파악하기 위하여 브랜드 명 과 판매되는 상품 카테고리를 기준으로 ‘여성복', '남 성복', ‘토털', ‘아웃도어웨어', ‘스포츠웨어', ‘이너웨 어', ‘아동복', ‘잡화', ‘신발'로 나누어 분석하였다.

패션존 분석의 경우, 한 개 브랜드의 팝업 스토어 를 운영하는 형태인 '패션기업 주체' 사례에서만 분석이 가능하므로, 전체 242 개 사례 중, 패션기업

〈Table 1〉 The fashion zone situations of fashion pop-up stores managed by fashion enterprises

\begin{tabular}{l|c|c}
\hline \multicolumn{1}{c|}{ Fashion zone } & Frequency & Percentage(\%) \\
\hline Total zone & 65 & 28.4 \\
\hline Women's wear zone & 59 & 25.8 \\
\hline Accessory zone & 47 & 20.5 \\
\hline Men's wear zone & 18 & 7.9 \\
\hline Shoes zone & 15 & 6.6 \\
\hline Sportswear zone & 9 & 3.9 \\
\hline Outdoorwear zone & 8 & 3.5 \\
\hline Kids' wear zone & 5 & 2.2 \\
\hline Innerwear zone & 3 & 1.3 \\
\hline \multicolumn{1}{c}{ Total } & 229 & 100.0 \\
\hline
\end{tabular}


주체 팝업 스토어 사례 229개를 대상으로 패션존에 대한 빈도 분석을 실시하였고, 그 결과는〈Table 1〉 과 같다.

패션존 분석 결과, 토털 존이 $28.4 \%$ 로 가장 높은 비율을 차지했으며, 다음으로 여성복 존 $25.8 \%$, 잡 화 존 $20.5 \%$ 의 순으로 높게 나타났다. 남성복 존, 신 발 존, 아웃도어 웨어 존, 스포츠 웨어 존은 각각 $7.9 \%, 6.6 \%, 3.9 \%, 3.5 \%$ 로 나타났으며, 아동복 존과 이너웨어 존이 각각 $2.2 \%, 1.3 \%$ 로 가장 낮은 비율로 운영되었음을 알 수 있다.

다음으로, 국내 패션 팝업 스토어의 패션존 변화 추이를 연도별로 알아보기 위해 패션기업 팝업 스 토어 229개 사례의 운영 시기와 패션존을 바탕으로 교차 분석을 실시하였으며, 그 결과는〈Table 2〉와 같다.

여성복 존 팝업 스토어의 경우, 2013년을 기점으 로 급격히 증가하였으며, 남성복, 여성복 및 잡화까 지 모두 취급하는 토털 존 팝업 스토어는 다른 패션 존에 비해 꾸준히 높은 수를 유지하며 증가하다가 2014년에는 전년 대비 감소하였다. 반면, 핸드백, 액 세서리 등의 상품군을 포함하는 잡화 존 팝업 스토 어는 2014년에 급격히 증가하였으며, 스포츠웨어 존 과 아웃도어 웨어 존 팝업 스토어도 2013년과 2014 년을 거치면서 점차적으로 증가하는 추세를 보이고 있다.

\section{The classification of spatial forms of fashion pop-up stores}

공간 형태에 따른 패션 팝업 스토어의 유형을 도
출하기 위하여 전체 242개 사례를 분석 및 분류한 결과, 14 개 유형으로 일 단계 분류되었으며, 이를 다 시 비슷한 특성을 지닌 유형으로 이 단계 분류 작업 하여 ‘유통업체 입점형', ‘이종산업 제휴형', ‘임시 공간 임대형', ‘온라인 형', ‘이동수단 활용형'과 같 이 5 개 유형으로 최종 분류하였다. 각 유형에 대한 특성은 다음과 같다.

첫 번째 유형은 ‘유통업체 입점형'이다. 이는 백 화점, 대형 복합 쇼핑몰, 아웃렛, 편집샵, 자사 대리 점 등의 유통업체에서 일정 기간 동안 팝업 스토어 를 운영하는 형태로, 해당 유통업체에 이미 입점되 어 있는 브랜드가 유통업체 내의 또 다른 공간에서 팝업 스토어를 운영하는 경우와 해당 유통업체에 입점되어 있지 않은 브랜드가 팝업 스토어 운영 기 간 동안만 입점하는 경우, 그리고 자사 대리점 및 플 래그십 스토어에서 제품을 한정 판매하거나, 일시적 인 이벤트 등을 진행하며, 팝업 스토어로 운영하는 경우가 이에 해당된다.

두 번째 유형은 ‘이종산업 제휴형'이다. 요식업체, 박물관, 미술관, 영화관, 각종 페스티벌 등과 같이 패션산업 이외의 산업체와 제휴 혹은 콜라보레이션 을 통해 팝업 스토어를 운영하는 경우가 이에 해당 된다.

세 번째 유형은 ‘임시 공간 임대형’이다. 2011년, 스트릿 캐주얼 브랜드 브라운브레스는 〈Fig. 2〉와 같이 브라운브레스 월이라는 갤러리 형태의 매장을 열었다. 브라운브레스 월은 ‘전시' 및 '팝업’을 목적 으로 기획되었고, 이후 잡화 브랜드 블랭코브, 남성 캐주얼 브랜드 브리즈웨이 등이 브라운브레스 월에

〈Table 2〉 The annual changes of fashion pop-up stores' fashion zone managed by fashion enterprises

\begin{tabular}{c|c|c|c|c|c|c|c|c|c|c}
\hline & $\begin{array}{c}\text { Women's } \\
\text { wear zone }\end{array}$ & $\begin{array}{c}\text { Men's } \\
\text { wear zone }\end{array}$ & $\begin{array}{c}\text { Total } \\
\text { zone }\end{array}$ & $\begin{array}{c}\text { Acc } \\
\text { zone }\end{array}$ & $\begin{array}{c}\text { Shoes } \\
\text { zone }\end{array}$ & $\begin{array}{c}\text { Sports } \\
\text { wear zone }\end{array}$ & $\begin{array}{c}\text { Outdoor } \\
\text { wear zone }\end{array}$ & $\begin{array}{c}\text { Inner } \\
\text { wear zone }\end{array}$ & $\begin{array}{c}\text { Kids' } \\
\text { wear zone }\end{array}$ & Total \\
\hline 2007 & 0 & 0 & 0 & 0 & 1 & 0 & 0 & 0 & 0 & 1 \\
\hline 2009 & 0 & 1 & 2 & 0 & 0 & 1 & 0 & 0 & 0 & 4 \\
\hline 2010 & 2 & 4 & 4 & 1 & 1 & 1 & 0 & 0 & 1 & 14 \\
\hline 2011 & 4 & 2 & 10 & 2 & 1 & 0 & 0 & 0 & 1 & 20 \\
\hline 2012 & 7 & 4 & 11 & 7 & 3 & 0 & 1 & 0 & 0 & 33 \\
\hline 2013 & 21 & 3 & 20 & 12 & 3 & 1 & 4 & 2 & 0 & 66 \\
\hline 2014 & 25 & 4 & 18 & 25 & 6 & 6 & 3 & 1 & 3 & 91 \\
\hline Total & 59 & 18 & 65 & 47 & 15 & 9 & 8 & 3 & 5 & 229 \\
\hline
\end{tabular}




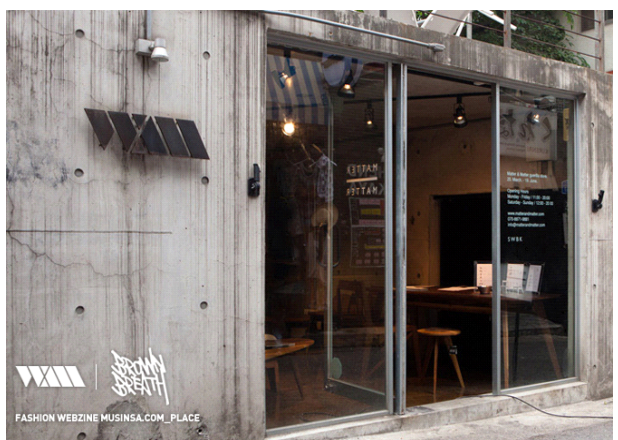

〈Fig. 2〉 Brownbreath wall

From. Sim (2011). http://www.musinsa.com

서 팝업 스토어를 열었다( $\mathrm{Sim}, 2011)$. 이와 같은 팝 업 전문공간을 임대하거나, 혹은 비어있는 점포를 일정기간 임대하여 운영하는 경우가 이에 해당된다.

네 번째 유형은 ‘온라인 형'이다. 이 유형은 Surchi (2011)가 제시한 팝업 스토어의 분류 중, '일시적 온 라인 스토어'에 해당되는 형태이다. 인터넷 도메인 계정을 일정 기간만 접속이 가능하도록 설정하여, 오 프라인 팝업 스토어의 특성을 그대로 온라인으로 가져와 운영하는 형태이다. 소비자는 팝업 기간 동 안만 온라인을 통해 제품을 구입하거나 살펴볼 수 있다.

다섯 번째 유형은 ‘이동수단 활용형'이다. 이것은

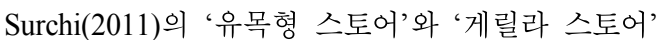
의 혼합 형태로써, 버스나 컨테이너 등을 개조하여 팝업 스토어로 운영하는 형태이다. 이동식 차량의 경우, 유동인구가 많은 지역을 돌아다니는 게릴라성 매장으로 이용하기도 한다.

\section{The situation and annual changes of fashion} pop-up stores' spatial forms

본 연구에서 도출한 매장 형태에 따른 유형을 바 탕으로, 국내 패션 팝업 스토어의 매장 형태의 현황 을 알아보기 위하여 국내 패션 팝업 스토어의 매장 형태에 따른 유형을 패션기업 주체와 유통업체 주 체로 대분하여 분석하였다.

먼저, 패션기업 주체 팝업 스토어 229개의 사례 를 대상으로 빈도 분석을 실시하였으며, 그 결과는 $\langle$ Table 3 과 같다.
〈Table 3〉 The spatial forms' situations of fashion pop-up stores managed by fashion enterprises

\begin{tabular}{l|c|c}
\hline Type of fashion pop-up stores & Frequency & $\begin{array}{c}\text { Percentage } \\
(\%)\end{array}$ \\
\hline $\begin{array}{l}\text { A type of opening in distri- } \\
\text { bution company }\end{array}$ & 193 & 84.3 \\
\hline $\begin{array}{l}\text { A type of alliance with diffe- } \\
\text { rent kinds of industries }\end{array}$ & 15 & 6.6 \\
\hline $\begin{array}{l}\text { A type of rental the temporary } \\
\text { space }\end{array}$ & 14 & 6.1 \\
\hline A type of opening in online & 4 & 1.7 \\
\hline $\begin{array}{l}\text { A type of using containers or } \\
\text { trucks }\end{array}$ & 3 & 1.3 \\
\hline
\end{tabular}

패션기업 주체 팝업 스토어는 '유통업체 입점형' 이 전체 중 $84.3 \%$ 로 가장 높은 비율을 차지하였으 며, ‘이종산업 제휴형', ‘임시 공간 임대형'이 각각 $6.6 \%, 6.1 \%$ 로 뒤를 이었고, '온라인 형'과 '이동수단 활용형'은 각각 $1.7 \%, 1.3 \%$ 로 매우 낮은 비율을 차 지하였다.

다음으로, 유통업체 주체 팝업 스토어 13 개의 사 례를 대상으로 빈도 분석을 실시하였으며, 그 결과 는 〈Table 4〉와 같다. 유통업체에서 주체하는 팝업 스토어를 대상으로 하였기 때문에, '유통업체 입점 형’이 $92.3 \%$ 로 대부분을 차지하였다.

다음으로, 국내 패션 팝업 스토어의 연도별 매장 형태에 따른 유형의 변화 추이를 알아보기 위하여 패션기업 주체 팝업 스토어 229개 사례의 운영 시기 와 매장 유형을 바탕으로 교차 분석을 실시하였으 며, 그 결과는〈Table 5〉와 같다.

패션기업 주체 팝업 스토어의 경우, 2007년에 '컨

〈Table 4〉 The spatial forms' situations of fashion pop-up stores managed by distribution enterprises

\begin{tabular}{c|c|c}
\hline Type of fashion pop-up stores & Frequency & $\begin{array}{c}\text { Percentage } \\
(\%)\end{array}$ \\
\hline $\begin{array}{l}\text { A type of opening in distri- } \\
\text { bution company }\end{array}$ & 12 & 92.3 \\
\hline $\begin{array}{l}\text { A type of rental the temporary } \\
\text { space }\end{array}$ & 1 & 7.7 \\
\hline \multicolumn{1}{c|}{ Total } & 13 & 100.0 \\
\hline
\end{tabular}


〈Table 5〉 The annual changes of fashion pop-up stores' spatial forms managed by fashion enterprises

\begin{tabular}{c|c|c|c|c|c|c}
\hline & $\begin{array}{c}\text { A type of opening } \\
\text { in distribution } \\
\text { company }\end{array}$ & $\begin{array}{c}\text { A type of alliance } \\
\text { with different kinds } \\
\text { of industries }\end{array}$ & $\begin{array}{c}\text { A type of rental } \\
\text { the temporary } \\
\text { space }\end{array}$ & $\begin{array}{c}\text { A type of } \\
\text { opening in online }\end{array}$ & $\begin{array}{c}\text { A type of using } \\
\text { containers or } \\
\text { trucks }\end{array}$ & Total \\
\hline 2007 & 0 & 1 & 0 & 0 & 0 & 1 \\
\hline 2009 & 1 & 0 & 2 & 0 & 1 & 4 \\
\hline 2010 & 12 & 0 & 0 & 0 & 2 & 14 \\
\hline 2011 & 11 & 5 & 3 & 1 & 0 & 20 \\
\hline 2012 & 26 & 2 & 5 & 0 & 0 & 33 \\
\hline 2013 & 58 & 2 & 3 & 3 & 0 & 66 \\
\hline 2014 & 85 & 5 & 1 & 0 & 0 & 91 \\
\hline Total & 193 & 15 & 14 & 4 & 3 & 229 \\
\hline
\end{tabular}

버스'가 홍대 카페 'HUT'와 콜라보레이션한 팝업 스토어를 선보였다. 이 후, 2009년부터 본격적으로 패션 팝업 스토어가 운영되기 시작하였으며, 2010 년까지는 주로 ‘유통업체 입점형'이 주를 이루었다. 2011년부터 '온라인 형'과 같은 새로운 유형이 등장 하였으며, 이전에 비해 팝업 스토어가 보다 다양한 형태로 운영되는 시기였음을 알 수 있다.

2011년 이후부터, 초기 팝업 스토어 형태인 '이동 수단 활용형’은 더 이상 나타나지 않았고, 2013년부 터 2014년 사이에는 ‘유통업체 입점형'이 급격히 증 가하면서 패션기업에서의 팝업 스토어 운영이 활발 해진 것으로 나타났다.

마지막으로, 유통업체 주체 팝업 스토어 13 개 사 례의 오픈 시기와 매장 유형을 바탕으로 교차 분석 을 실시하였으며, 그 결과는 〈Table 6〉과 같다.

유통업체 주체 팝업 스토어의 경우, 2010년 3월, 현대백화점 목동점에서 ‘프로젝트 런웨이 코리아 시

〈Table 6〉 The annual changes of fashion pop-up stores' spatial forms managed by distribution enterprises

\begin{tabular}{c|c|c|c}
\hline & $\begin{array}{l}\text { A type of opening in } \\
\text { distribution company }\end{array}$ & $\begin{array}{c}\text { A type of rental the } \\
\text { temporary space }\end{array}$ & Total \\
\hline 2010 & 1 & 0 & 1 \\
\hline 2011 & 1 & 0 & 1 \\
\hline 2012 & 1 & 0 & 1 \\
\hline 2013 & 5 & 1 & 6 \\
\hline 2014 & 4 & 0 & 4 \\
\hline Total & 12 & 1 & 13 \\
\hline
\end{tabular}

즌 1 '에 참가했던 신진 디자이너 5 명의 신규 브랜드 제품을 판매하는 팝업 스토어를 오픈한 것을 시작 으로, 신세계 백화점, 롯데백화점 등 다른 유통업체 에서도 내 - 외부 행사장에서 신진 디자이너 브랜드 팝업 스토어 등을 운영하였다(Nam, 2010). 이 후 2013 년부터 ‘유통업체 입점형’의 팝업 스토어의 수가 이 전에 비해 다소 증가한 것으로 나타났다.

\section{The classification of fashion pop-up stores'} management purposes

운영 목적에 따른 패션 팝업 스토어의 유형을 도 출하기 위하여 전체 242 개 사례를 분석 및 분류한 결과, 9 개 유형으로 일 단계 분류되었으며, 이를 다 시 비슷한 특성을 지닌 유형으로 이 단계 분류 작업 하여 ‘제품 소개형', '가격 할인형', ‘프로모션형', ‘장 소 및 채널 검증형', ‘인재 양성형'과 같이, 5 개 유형 으로 최종 분류하였다. 각 유형에 대한 특성은 다음 과 같다.

첫 번째 유형은 '제품 소개'에 초점을 맞추어 운 영한 유형이다. 이는 신제품, 한정품과 같이, '제품' 을 소개하거나 판매할 목적으로 운영되는 경우이다.

두 번째 유형은 '가격 할인'에 초점을 맞추어 운 영한 유형으로, 팝업 스토어 운영 기간 동안 제품의 가격을 할인하여 제공하기 위한 목적으로 운영되는 경우이다.

세 번째 유형은 ‘프로모션'에 초점을 맞추어 운영 한 유형으로, 브랜드 이미지를 홍보하거나, 체험 마 케팅, 증정 프로모션 등의 이벤트를 제공하기 위해 
운영되는 경우이다.

네 번째 유형은 '장소 및 채널 검증'에 초점을 맞 추어 운영한 유형으로, 본격적인 매장 전개에 앞서 매장의 가능성을 검증하거나, 유통 채널 확장 등을 위해 팝업 스토어를 이용하는 경우이다.

다섯 번째 유형은 '인재 양성'에 초점을 맞추어 운영한 유형이다. 이는 팝업 스토어 운영을 통해 신 진 디자이너 혹은 브랜드를 지원하고, 발전 가능성 이 있는 디자이너나 브랜드를 발굴하기 위해 팝업 스토어를 운영하는 경우이다.

\section{The situation and annual changes of fashion}

\section{pop-up stores' management purposes}

본 연구에서 도출한 운영 목적에 따른 유형을 바 탕으로, 국내 패션 팝업 스토어의 운영 목적 현황을 패션기업 주체와 유통업체 주체로 대분하여 분석하 였다.

운영 목적의 경우, 하나의 팝업 스토어에서 다수 의 목적을 포함하고 있는 사례가 있었으므로, 중복 카운트를 허용하였다.

먼저, 패션기업 주체 팝업 스토어 229개의 사례 를 대상으로 빈도 분석을 실시하였고, 그 결과는 〈Table 7 과 같다.

패션기업 주체 팝업 스토어의 목적은 '제품 소개 형’이 $44.7 \%$ 로 가장 높은 비율을 차지하였으며, 다 음으로 ‘장소 및 채널 검증형', ‘프로모션형'이 각각 $24.6 \%, 19.8 \%$ 로 뒤를 이었다. 팝업 스토어가 일시적 인 마케팅 수단인 만큼, 신제품이나 새로운 라인을

〈Table 7〉 The management purposes' situations of fashion pop-up stores managed by fashion enterprises (Multiple response analysis)

\begin{tabular}{l|c|c}
\hline Type of fashion pop-up stores & Frequency & $\begin{array}{c}\text { Percentage } \\
(\%)\end{array}$ \\
\hline Product introduction & 131 & 44.7 \\
\hline Price discount & 29 & 9.9 \\
\hline Promotion & 58 & 19.8 \\
\hline $\begin{array}{l}\text { Possibility testing of location } \\
\text { and chanel }\end{array}$ & 72 & 24.6 \\
\hline Cultivation of new brand & 3 & 1.0 \\
\hline \multicolumn{1}{c|}{ Total } & 229 & 100.0 \\
\hline
\end{tabular}

〈Table 8〉 The management purposes' situations of fashion pop-up stores managed by distribution enterprises (Multiple response analysis)

\begin{tabular}{l|c|c}
\hline Type of fashion pop-up stores & Frequency & $\begin{array}{c}\text { Percentage } \\
(\%)\end{array}$ \\
\hline Product introduction & 2 & 15.5 \\
\hline $\begin{array}{l}\text { Possibility testing of location } \\
\text { and chanel }\end{array}$ & 1 & 7.6 \\
\hline Cultivation of new brand & 10 & 76.9 \\
\hline \multicolumn{1}{c|}{ Total } & 13 & 100.0 \\
\hline
\end{tabular}

런칭하면서 팝업 스토어를 운영하여 이를 이슈화 시 키거나, 콜라보레이션 제품, 한정품 등을 팝업 스토 어 기간 동안만 판매하여 단기간에 높은 매출을 올 리기 위해 팝업 스토어를 이용하는 경우가 많음을 알 수 있었다.

다음으로, 유통업체 주체 팝업 스토어 13 개의 사 례를 대상으로 빈도 분석을 실시하였으며, 그 결과 는 〈Table 8 〉과 같다. 유통업체 주체 팝업 스토어의 목적은 ‘인재 양성형'이 $76.9 \%$ 로 가장 높은 비율을 차지하였으며, 다음으로 '제품 소개형', ‘장소 및 채 널 검증형'이 각각 $15.5 \%, 7.6 \%$ 로 뒤를 이었다.

다음으로, 국내 패션 팝업 스토어의 연도별 운영 목적에 따른 유형의 변화 추이를 알아보기 위하여 패션기업 주체 팝업 스토어 229개 사례의 운영 시기 와 목적 유형을 바탕으로 교차 분석을 실시하였으 며, 그 결과는〈Table 9〉와 같다.

패션기업 주체 팝업 스토어의 경우, 팝업 스토어 등장 초기인 2007년부터 2009년까지는 ‘제품 소개 형'과 ‘프로모션형'이 주를 이루었으나, 2010년에는 '가격 할인형'과 '장소 및 채널 검증형'이, 2011년에 는 ‘인재 양성형'이 등장하였다. 2012년에는 다른 유형에 비해 ‘장소 및 채널 검증형'의 팝업 스토어가 상당히 높은 비율로 증가하였으며, 2013년과 2014년 을 거치면서 패션기업 주체 팝업 스토어의 목적은 대부분 '제품 소개'에 집중되어 있음을 알 수 있다.

마지막으로, 유통업체 주체 팝업 스토어 13 개 사 례의 오픈 시기와 목적 유형을 바탕으로 교차 분석 을 실시하였으며, 그 결과는〈Table 10 과 같다.

유통업체 주체 팝업 스토어는 주로 가능성 있는 브랜드나 신진 디자이너를 발굴하기 위하여 '인재 
〈Table 9〉 The annual changes of fashion pop-up stores' management purposes managed by fashion enterprises (Multiple response analysis)

\begin{tabular}{c|c|c|c|c|c|c}
\hline & $\begin{array}{c}\text { Product } \\
\text { introduction }\end{array}$ & Price discount & Promotion & $\begin{array}{c}\text { Possibility testing } \\
\text { of location and } \\
\text { chanel }\end{array}$ & $\begin{array}{c}\text { Cultivation of } \\
\text { new brand }\end{array}$ & Total \\
\hline 2007 & 0 & 0 & 1 & 0 & 0 & 1 \\
\hline 2009 & 4 & 0 & 2 & 0 & 0 & 4 \\
\hline 2010 & 9 & 1 & 4 & 2 & 0 & 14 \\
\hline 2011 & 12 & 2 & 4 & 4 & 1 & 21 \\
\hline 2012 & 13 & 5 & 4 & 15 & 0 & 32 \\
\hline 2013 & 34 & 13 & 15 & 21 & 2 & 66 \\
\hline 2014 & 59 & 8 & 28 & 30 & 0 & 91 \\
\hline Total & 131 & 29 & 58 & 72 & 3 & 229 \\
\hline
\end{tabular}

$\langle$ Table 10〉 The annual changes of fashion pop-up stores' management purposes managed by distribution enterprises (Multiple response analysis)

\begin{tabular}{c|c|c|c|c}
\hline & $\begin{array}{c}\text { Product } \\
\text { introduction }\end{array}$ & $\begin{array}{c}\text { Possibility testing } \\
\text { of location and chanel }\end{array}$ & $\begin{array}{c}\text { Cultivation of } \\
\text { new brand }\end{array}$ & Total \\
\hline 2010 & 0 & 0 & 1 & 1 \\
\hline 2011 & 0 & 0 & 1 & 1 \\
\hline 2012 & 0 & 0 & 5 & 1 \\
\hline 2013 & 1 & 0 & 2 & 6 \\
\hline 2014 & 1 & 1 & 10 & 13 \\
\hline Total & 2 & 1 & & 4 \\
\hline
\end{tabular}

양성’을 목적으로 두고 운영하는 경우가 대부분이 었지만, 2013년부터는 '제품 소개', ‘장소 및 채널 검증’을 위해서 팝업 스토어를 운영한 사례가 증가 하기 시작하였다.

\section{Conclusion}

본 연구는 오늘날 패션 시장에서 활발히 운영되 고 있는 국내 팝업 스토어 사례 분석을 통해 운영 주체별 분류와 패션존 현황 및 변화 추이를 분석하 였을 뿐만 아니라, 국내 전개 패션 팝업 스토어의 유 형을 도출하고, 공간 형태 및 운영 목적에 따른 팝업 스토어의 변화 양상을 살펴봄으로써, 향후 팝업 스 토어를 이용한 마케팅 전략 수립에 도움을 주고자 하였다. 본 연구의 결과를 요약하면 다음과 같다.

첫째, 국내 패션 팝업 스토어는 2007년에 처음으
로 나타났으며, 2012년도까지 패션 팝업 스토어의 수가 점진적으로 증가하였고, 2013년도부터는 그 수가 급격히 증가하였다. 이를 통해 2007년은 국내 패션 팝업 스토어의 소개기로, 그리고 2013년도부 터 현재까지는 성장기로 볼 수 있으며, 이의 지속 여 부는 당분간 지켜보아야 할 것이다.

둘째, 국내 패션 팝업 스토어의 패션존 분석 결 과, ‘토털 존'이 가장 높은 비율을 차지했으며, 다음 으로 '여성복 존', ‘잡화 존', '남성복 존' 등의 순으 로 나타났다. 특히, 최근 ‘잡화 존' 패션 팝업 스토어 가 급증하였고, '아웃도어 웨어 존'과 '스포츠 웨어 존'도 비교적 증가한 것으로 나타났는데, 이는 패션 업계의 경기 침체로 인해 기업들이 비교적 유행이 나 시즌에 영향을 받지 않아 실패율이 적은 잡화 라 인을 강화하고 있는 패션 비즈니스의 현실과 최근 의 레저, 캠핑 등 아웃도어 활동의 유행으로 인해 스 
포츠 및 아웃도어 웨어의 판매가 증가하고 있는 상 황이 팝업 스토어 운영에도 일부 반영된 결과로 볼 수 있을 것이다.

셋째, 국내 패션 팝업 스토어의 매장 유형 분류는 운영주체에 따라 '패션기업 주체형'과 ‘유통업체 주 체형'이 도출되었으며, 공간 형태에 따라 ‘유통업체 입점형', ‘이종산업 제휴형', ‘임시 공간 임대형', ‘온 라인 형', ‘이동수단 활용형'과 같이 총 5 가지 유형 이 도출되었다. 또한, 운영 목적에 따라 '제품 소개 형', ‘가격 할인형', ‘프로모션형', ‘장소 및 채널 검 증형', ‘인재 양성형' 등 5 가지 유형이 도출되었다.

넷째, 패션 팝업 스토어의 매장 형태 유형의 누적 현황에서, ‘유통업체 입점형’이 가장 높은 비율을 차지하였는데, 그 운영 목적이 '제품 소개'와 '장소 및 채널 검증'에 집중되어 있는 것으로 보아, 유동 고객이 많고, 접근성이 높은 유통업체의 장점과 함 께, 유통채널을 확장시키는 기회로 활용할 수 있기 때문일 것으로 사료된다.

다섯째, 패션기업 주체 팝업 스토어의 운영 목적 유형은 ‘장소 및 채널 검증형'이, 유통업체 주체 팝 업 스토어의 운영 목적 유형은 ‘인재양성 형'이 비 교적 높은 비율을 차지하고 있다는 차별점이 있었 다. 이는 다양한 위험요소가 존재하는 소비 시장에 서, 패션기업 입장에서는 시장의 가능성을, 유통업 체 입장에서는 브랜드의 가능성을 판단하기 위해 팝업 스토어를 이용한 것으로 사료된다.

여섯째, 패션 팝업 스토어 등장 초기에는 주로 ‘유통업체 입점형'의 팝업 스토어가 ‘제품 소개'와 ‘프로모션'의 목적으로 운영되는 경우가 대부분이었 으나, 시간이 지남에 따라 '온라인 형'등 새로운 형태 의 팝업 스토어가 생겨났으며, '가격 할인' 및 '장소 및 채널 검증'의 목적으로 운영되는 등, 팝업 스토어 가 이전에 비해 보다 다양한 형태와 목적으로 운영 되고 있음을 알 수 있었다.

그러나 2013년 이후, 패션기업 주체 팝업 스토어 의 목적 유형은 대부분 '제품 소개형'에 집중되어 있었고, 이전에는 '인재 양성'의 목적으로만 팝업 스토어를 운영하던 유통업체 주체 팝업 스토어에서 도 '제품 소개'의 목적이 등장한 것을 알 수 있는데, 이는 경기 침체로 인한 패션 제품 판매율의 감소로 인해, 패션기업과 유통업체에서 팝업 스토어의 특성
을 이용한 단기적 매출 상승효과를 기대하고 있는 것으로 볼 수도 있다.

이상의 연구결과로, 향후 패션기업 또는 유통업 체의 팝업 스토어 마케팅 전략에 대해 다음과 같이 제언하고자 한다.

우선, 팝업 스토어는 현재 매장 형태 및 운영 목 적 등의 측면에서 점차 다양화 되어 가고 있으며, 앞 으로도 상당히 많은 수의 팝업 스토어가 운영될 것 으로 예측되므로, 이를 이용하는 기업에서는 보다 인상 깊고 특색 있는 팝업 스토어 구색을 통해 소비 자로 하여금 타 매장에 비해 더욱 긍정적 체험을 경 험하고, 그 체험에 대한 기억이 지속될 수 있도록 기 획하여야 할 것이다.

또한, 유통업체에 입점하거나, 유동인구가 많은 지역에 팝업 스토어를 오픈한다 하더라도 최근 경기 침체로 인해 소비심리가 감소하고 있는 추세이기 때 문에, 팝업 스토어 오픈에 대한 적극적인 홍보를 통 해 좀 더 많은 방문 소비자를 유치하려는 노력을 기 울여, 이를 통한 마케팅 효과가 보다 극대화 될 수 있도록 해야 할 것이다. Kim and Lee(2012)의 연구 에서도 알 수 있듯이, 팝업 스토어는 소규모의 일시 적인 공간이지만, 경제적 측면과 파급효과가 매우 뛰 어나므로, 이를 패션시장의 변화에 맞게 좀 더 효율 적인 공간으로 이용할 수 있도록 하여야 할 것이다. 본 연구는 패션 팝업 스토어를 운영주체별로 '패 션기업 주체형'과 ‘유통업체 주체형'으로 대분하고, 이들 각각을 다시 공간 형태에 따라 '유통업체 입점 형’, ‘이종산업 제휴형', ‘임시 공간 임대형', ‘온라인 형', ‘이동수단 활용형'의 5 가지 유형으로 분류 및 제시하였으며, 운영 목적에 따라 ‘제품 소개형', ‘가 격 할인형', ‘프로모션형', ‘장소 및 채널 검증형', '인재 양성형' 등 5 가지 유형으로 분류 및 제시하여 이들을 서로 비교 분석해봄으로써 아직까지 학문적 으로 이루어지지 못한 패션 팝업 스토어의 유형을 체계화시키고, 향후 패션 팝업 스토어 연구에 초석 을 마련했다는 데 그 의의가 있다고 본다. 그럼에도 불구하고, 본 연구는 패션 팝업 스토어에 대한 기사 를 토대로 자료를 수집하였기에 이 과정에서 기사 화 되지 않았거나, 화제가 되지 않은 소수의 사례들 은 제외되었을 가능성이 있다. 또한, 팝업 스토어의 유형 분류에 있어서 각 구성원들의 회의를 통해 유 
형을 분류함으로써 구성원 간의 수치적인 신뢰도 검증 과정을 거치지 못하였다는 한계가 있었다. 이 와 같은 한계점을 보완하기 위해 후속연구에 대해 다음과 같이 제언하고자 한다.

첫째, 패션 팝업 스토어를 기획한 기업의 의도와 목적을 명확히 파악하기 위해 팝업 스토어를 기획 및 운영한 관계자의 심층 면접을 시행하고, 이를 토 대로 한 질적 연구를 진행하여 본 연구에서 도출된 매장 형태와 목적 유형에 대한 검증이 시행되어야 할 것이다.

둘째, 본 연구에서 도출된 각 유형별 비율 및 변 화상과 소비자 입장에서 인지된 패션 팝업 스토어 의 유형을 비교 - 분석하여, 보다 실질적이고 구체적 인 마케팅적 제언을 가능케 하여야 할 것이다.

셋째, 패션 머천다이징 분야의 학자 및 기업인 등, 다수의 피 실험자에 의해 본 연구에서 제시하고 있는 유형에 대해 평가한 후, 이에 대해 서로 간의 신뢰도를 분석하여 본 연구에서 제안하고 있는 팝 업 스토어 유형을 검증, 평가 및 보완할 수 있도록 해야 할 것이다.

\section{References}

Bauman, Z., \& Favaro, S. (2010). Liquid times: Living in an age of uncertainty. Cambridge: Polity Press.

Chae, H. J., Choi, H. Y., Jang, J. H., \& Ko, E. J. (2012). The influence of pop-up store attributions toward brand attitude and revisiting intention: Focus on sports brands. Fashion \& Textile Research Journal, 14(3), 400-412. doi:10.5805/KSCI.2012. 14.3.400

Jang, S. Y. (2012, March 8). ⿱ㅡ夫 온라인 시장의 새로 운 키워드 ' $\mathrm{F}$ 커머스와 팝업 스토어' [USA, The new keyword in online market ' $F$ Commerce and Pop-up Store']. KOTRA, Retrieved December 20, 2014, from http://www.globalwindow.org/gw/over market/GWOMAL020M.html?BBS_ID=10\&ME NU_CD $=$ M10103\&UPPER_MENU_CD $=$ M1010 $2 \&$ MENU_STEP $=3 \&$ ARTICLE_ID $=2148049 \&$ ARTICLE_SE $=20302$

Kim, H. J., \& Lee, J. K. (2012). A study on the spatial characteristics of pop-up store applied experiential marketing. Journal of Korea Institute of Spatial Design, 7(1), 77-86.

Kim, J. S. (2010). The influence of pop-up store experiences on brand attitudes. Unpublished master's thesis, Hongik University, Seoul, Korea.

Kim, S. Y. (2010). Classifications of Korean fashion multi-brand stores and their strategic directions. Unpublished master's thesis, Konkuk University, Seoul, Korea.

Kim, S. Y., \& Kim, C. S. (2011). Comparison of feel/ sense and purchase behavior among NIKE, PUMA, and KUHO POP-UP store visitors. The Research Journal of the Costume Culture, 19(6), 1288-1301.

Kim, Y. K., \& Kim, Y. I. (2013). Analysis of VMD characteristic of department pop-up store: Focus on Seoul, Busan, Daegu and Osaka. Korea Science \& Art Forum, 14, 77-90.

Lim, K. R. (2012, November 16). 유통가에 오디션 바람 [The fever of auditions in the distribution markets]. Apparel News, Retrieved December 31, 2014, from http://www.apparelnews.co.kr/naver/ view.php?iid=44699

Lisanti, T. (2014, December). Pop-ups reflect retail trends. License! Global 17(6), 7.

Marciniak, R., \& Budnarowska, C. (2009, July). Marketing approaches to pop up stores: An exploration of social networking. Paper presented at the 15th Conference of the European Association of Education and Research in Commercial Distribution (EAERCD), Guildford, Surrey, England. Retrieved July 15, 2015, from http://eprints.bournemouth. ac.uk/15678/2/EAERCD_2009_Marciniak_\%26_ Budnarowska.pdf

Nam, S. G. (2010, February 22). 현대백화점, 프런코 팝업스토어 연다! [Hyundai Department Store will open the pop-up store of the TV show, Project runway Korea]. bntnews, Retrieved December 31, 2014, from http://bntnews.hankyung.com/apps/ news?popup $=0 \&$ nid $=02 \& \mathrm{c} 1=02 \& \mathrm{c} 2=02 \& \mathrm{c} 3=00$ $\&$ nkey $=201002221440193 \&$ mode $=$ sub_view 
Niehm, L. S., Fiore, A. M., Jeong, M. Y., \& Kim, H. J. (2006). Pop-up retail's acceptability as an innovative business strategy and enhancer of the consumer shopping experience. Journal of Shopping Center Research, 13(2), 1-30.

Picot-Coupey, K. (2014). The pop-up store as a foreign operation mode (FOM) for retailers. International Journal of Retail \& Distribution Management, 42(7), 643-670. doi:10.1108/IJRDM-01-2013-0032

Shin, J. S. (2013). Brand identity strategy with space marketing methodology: Focusing on the pop-up store. Unpublished master's thesis, Kookmin Uni- versity, Seoul, Korea.

Sim, J. S. (2011, July 5). A new Message of Brownbreath. Retrieved December 31, 2014, from https:// www.musinsa.com/?m=magazine $\&$ bid=magazine $\& c a t=$ FASHION_NEWS\&p=10\&uid=1761\&bra $\mathrm{nd}=\&$ scopt $=\&$ init

Subvertising. (2009, September). Temporary stores and guerrilla stores (in Italian). 21, p.16.

Surchi, M. (2011). The temporary store: A new marketing tool for fashion brands. Journal of Fashion Marketing and Management, 15(2), 257-270. 